\title{
Challenges in Making Differential Diagnosis of Psychiatric Illness: An Occupational Therapy Perspective
}

\section{Emily Frances Piven ${ }^{1,2 *}$}

${ }^{1}$ Retired Associate Professor of Occupational Therapy, University of Texas at El Paso, Rehabilitation Sciences Department, USA ${ }^{2}$ Health Matters First of Florida, Inc., Oakland, Florida, USA

Keywords: Psychosocial occupational therapy, Psychiatry, Mental illness

This editorial has offered a commentary about the article, Limitations of Clinical Psychiatric Diagnostic Measurements by Aden Jacob, a research scientist working at the Gray Institute for Radiation Oncology and Radiobiology, Medical Physics Radiotherapy at the University of Oxford in the United Kingdom [1].

My first reaction to the article was, "Why would an oncologist write an article about the American Medical Association's limitations in classification of psychiatric diagnoses? My curiosity led me to Google to search for answers. I found the author's website. I did not seek this information to belittle or challenge the author's credentials. I thought that other readers might be curious as well.

Linked In said that the author was currently at the University of California Medical Center in San Francisco, California and indicated that he was a biomedical engineer and neuroscientist at Nano Axis in New York [2]. His previous employment included University of Oxford, University of Pennsylvania and Cedars-Sinai Medical Center in Los Angeles, California. In addition, I found that the author's Twitter website contained a long list of links that explained his thoughts about various biomedical and neuro-ethical topics such as: cancer treatment, radiosurgery, Alzheimer's disease, tissue engineering, use of nanoparticles to cure tumors, stem cell research, Parkinson's disease, and other interesting and farsighted topics [3]. I also found his comments about "the failure of psychiatry" and "the biggest problem with mental health" [4].

Occupational therapy is a rehabilitation profession that helps a person with disease to improve their ability to function in everyday life activities or to adapt to their environmental demands, in order to continue to function to the best of their abilities [5]. Occupational therapy had its beginnings in psychiatric hospitals nearly 100 years ago, which has maintained its concerns about the psychosocial functioning of people of all ages and in all settings, wherever occupational therapists provide their services [5]. I am an occupational therapist, hence the selection of this article for my commentary.

The author spent most of the article reviewing the criteria for specific disorders, in order to illustrate his main point, which seemed to be that differential diagnosis was a complicated process that relied on self-report by patients and observation of their behavioral characteristics and manifestations, which were considered abnormal by others and pointed to a particular mental illness. Differential diagnosis, the art and science of distinguishing components of one disorder from several other disorders that share similar symptoms, has challenged even the best of psychiatrists. A psychiatrist must cluster the symptoms and behaviors under specific groupings, in order to determine that the majority of symptoms would be indicative of one specific diagnosis. The DSM has provided psychiatrists with the option of identifying other diagnoses that must continue to be ruled out.

Accurate psychiatric diagnosis has been linked to psychopharmacology because psychiatry changed dramatically subsequent to the onset of drug therapy. Talking to a psychiatrist for counseling about one's problems has been reserved for the purpose of initial evaluation. Well-insured psychiatric patients would be referred to receive limited counseling sessions with other professionals. Those lacking insurance with severe mental illness, would be referred to state facilities and free clinics for access to medications and ongoing follow-up. Psychiatrists usually have provided patients on medication with a series of 15 minute medication and laboratory report checks, to monitor the blood levels, side effects and toxicities of the medication (s) that were selected by the psychiatrist to treat the illness. For example, psychotropic medications have been used to decrease symptoms and manage behaviors associated with: serious thought disorders (as in schizophrenia), reduction of the temptation to ingest alcohol (as in alcoholism), reduction of anxiety (as in anxiety disorders), improvement of mood (as in depressive disorders), control of mania (as in bipolar disorders), and improvement of attention, organization, and concentration (as in attention deficit disorders), etc. The medications provided necessary brain chemicals to excite receptors in neural pathways that were found to be lacking in particular disorders, which prevented the brain to work as it should. The lack of patient response on a prescribed medication was an indication to the psychiatrist that he/ she might have made an incorrect diagnosis.

Medications were targeted to work with specific diagnoses have been beneficial for the masses. What had been accomplished in the environment of therapeutic milieu was greatly accelerated by drug therapy. Long term treatment for mental illness ended in the 1970s, sending people with serious psychoses to live on the streets and beaches. Sadly, this was not the intention, but there were no well-established provisions for further care.

For 16 years, I was fortunate to work with a brilliant, pioneering psychiatrist who exclusively practiced orthomolecular psychiatry in inpatient and outpatient settings. Orthomolecular psychiatry purported to balance brain nutrients to improve function and replace brain deficiencies. It has been criticized as non-effective because of a lack of sufficient research using randomized controlled trials. I had the pleasure of working with the patients who quickly responded to the nutrients. For example, one 20 years old male, who I will call Mike, was diagnosed with paranoid schizophrenia and obsessive compulsive personality disorder, because he clearly met the criteria for each disorder, as determined by

*Corresponding author: Emily Frances Piven, Health Matters First of Florida, Inc., Associate Editor of Occupational Therapy International, Retired Associate Professor of Occupational Therapy, Tel: 915-203-0718; E-mail: emilyh@utep.edu

Received February 20, 2014; Accepted February 22, 2014; Published February 25, 2014

Citation: Piven EF (2014) Challenges in Making Differential Diagnosis of Psychiatric Illness: An Occupational Therapy Perspective. J Neurol Disord 2: e110. doi:10.4172/2329-6895.1000e110

Copyright: @ 2014 Piven EF. This is an open-access article distributed under the terms of the Creative Commons Attribution License, which permits unrestricted use, distribution, and reproduction in any medium, provided the original author and source are credited. 
DSM-III criteria that was used from 1980 to 1987 [6]. Mike's maternal grandfather had the same disorder at 30 years of age, and had to quit his job as the principal of a high school. Mike's grandfather spent the rest of his life with disability. Mike had been treated with an abundance of drug trials that did not significantly improve his thought disorder and/ or his obsessive compulsive behavioral manifestations. In reality, Mike was diagnosed with histadelia, a condition that involved excess levels of histamine and basophils in the blood [7]. He was treated with benadryl, methionine, B6, calcium orotate and other nutrients that eliminated the paranoia and repetitive compulsions, in a matter of days. Mike was a case example of a physician who looked for answers, found the right diagnosis in the literature, and chose the right biochemical solution using an over the counter medication along with dietary supplements in a complementary fashion. Mike returned to his previous normal behavior of going to college, singing, and playing his guitar. Mike later married, had children, and became a productive member of society.

The author cites the Positive and Negative Syndrome Scale (PNSS) as an example of a medical scale that has been used to determine symptom severity in schizophrenia [8]. The author indicated that the PNSS was used world-wide since 1987, but had recently been challenged as inaccurate, due to the miscalculation of scores [9]. He suggested that similar scales needed to be developed to reflect the severity of behavioral symptoms. Severity of symptomatology was not a consideration in the newest guidelines provided in the DSM-5 [10].

I agree that the author offered a positive suggestion; however, the practicality of his suggestion must be considered. Diagnosis in psychiatry has not been perfect. Standardization of behavioral checklists for each diagnosis would require enormous efforts by willing psychiatrists, who would need to be motivated towards making this kind of contribution to the field and adequately funded to do the research. Perhaps this would attract psychiatrists, who are faculty at medical schools and already seek the funding to do meaningful research.

Furthermore, if orthomolecular psychiatry is to be accepted in the future, forward thinking psychiatrists who have practiced this nutrition-based form of psychiatry will also need to perform funded randomized controlled trial studies, in order to have their nutritional approach accepted into mainstream medicine. This is not likely to happen any time in the near future, until the Food and Drug Administration (FDA) gains control of the dietary supplements. There has been much resistance to three FDA attempts to regulate the vitamin supplement market, in order to protect consumers [11]. Currently, only physicians can prescribe nutrients to mitigate disease, but probably most physicians don't realize that they are capable of doing that. Physicians currently do not receive much training about nutritional supplementation. Physicians practicing this form of psychiatry must pull from the biochemistry background that enabled them to get accepted to medical school, in order to learn nutritional medicine on their own.

The author seems to be an "out of the box" thinker. It should be said that it has been the creative free thinkers in our society have advanced medicine to where has grown today. Yet, changing mainstream thinking has historically been a very slow process.

\section{References}

1. Jacob A (2013) Limitations of Clinical Psychiatric Diagnostic Measurements. J Neurol Disord 2: 122-126.

2. http://www.aydenjacobmedicine.com/failures-of-psychiatry.html.

3. Jacob A (2014) Ayden Jacob Med Twitter account.

4. http://www.aota.org/en/About-Occupational-Therapy.aspx.

5. http://www.psychiatry.org/practice/dsm/dsm-history-of-the-manual

6. Pfeiffer CC, Smyrl EG, lliev V (1972) Extreme basophil counts and blood histamine levels in schizophrenic outpatients as compared to normals. Res Commun Chem Pathol Pharmacol 4: 51-59.

7. Kay SR, Fiszbein A, Opler LA (1987) The positive and negative syndrome scale (PANSS) for schizophrenia. Schizophr Bull 13: 261-276.

8. Obermeier M, Schennach-Wolff R, Meyer S, Möller HJ, Riedel M, et al. (2011) Is the PANSS used correctly? a systematic review. BMC Psychiatry 11: 113.

9. Svenaeus $F$ (2013) Diagnosing mental disorders and saving the normal American Psychiatric Association, 2013. Diagnostic and statistical manual of mental disorders, 5thedn American Psychiatric Publishing: Washington, DC

10. http://archive.lewrockwell.com/paul/paul 288.html. 